\title{
Intervening in Student Identity in Mathematics Education: An Attempt to Increase Motivation to Learn Mathematics
}

\author{
Kayla Heffernan ${ }^{1 *}$, Steven Peterson ${ }^{2}$, Avi Kaplan ${ }^{3}$, Kristie J. Newton ${ }^{4}$ \\ ${ }^{1}$ Department of Mathematics, University of Pittsburgh at Greensburg, 150 Finoli Drive, Greensburg, PA 15601, USA \\ ${ }^{2}$ Haverford High School, 200 Mill Road, Havertown, PA 19083, USA \\ ${ }^{3}$ Department of Psychological Studies in Education, Temple University, 1301 Cecil B. Moore Avenue, Philadelphia, PA 19122, USA \\ ${ }^{4}$ Department of Teaching and Learning, Temple University, 1301 Cecil B. Moore Avenue, Philadelphia, PA 19122, USA

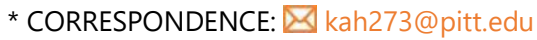

\begin{abstract}
Students' relationships with mathematics continuously remain problematic, and researchers have begun to look at this issue through the lens of identity. In this article, the researchers discuss identity in education research, specifically in mathematics classrooms, and break down the various perspective on identity. A review of recent literature that explicitly invokes identity as a construct in intervention studies is presented, with a devoted attention to research on identity interventions in mathematics classrooms categorized based on the various perspectives of identity. Across perspectives, the review demonstrates that mathematics identities motivate action and that mathematics educators can influence students' mathematical identities. The purpose of this paper is to help readers, researchers, and educators understand the various perspectives on identity, understand that identity can be influenced, and learn how researchers and educators have thus far, and continue to study identity interventions in mathematics classrooms.
\end{abstract}

Keywords: mathematics identity, motivation, identity perspectives

\section{INTRODUCTION}

Too often, students believe that learning mathematics requires a natural ability they do not possess (Blackwell et al., 2007). Many students experience classroom mathematical practices as being monotonous and devoid of meaning (Boaler et al., 2000). Also, countless students view mathematics as irrelevant to their present and future lives outside of the classroom (Anderson, 2007). The National Assessment of Educational Progress (1996) states that when progressing through school, students become more likely to say that they would choose to opt-out of studying mathematics if given a choice. Students also have fewer positive attitudes toward mathematics and are less likely to endorse the social importance of mathematics (Wilkins \& Ma, 2003). Consequently, many students abandon mathematical studies as early as possible and thereby limit their opportunities (Black et al., 2009), such as college enrollment and career prospects. In a world of ever-increasing advances in science, technology, engineering, and mathematics (STEM) fields, such outlooks on mathematics pose an issue for our society. Thus, education systems need to find ways to change students' negative outlooks on mathematics and increase student motivation to learn mathematics as well as other STEM subjects.

Increasingly, scholars have been viewing such undesirable phenomena through the lens of mathematics identity - experiences of dissonance between mathematics students' sense of whom they are and their perceptions of who they are expected to be in mathematics classrooms (Boaler \& Greeno, 2000). Until recently, there has been a lamentable dearth of insight into how teachers and instructors can encourage positive

Article History: Received 21 February $2020 \bullet$ Revised 15 May $2020 \bullet$ Accepted 27 May 2020

(C) 2020 by the authors; licensee Modestum Ltd., UK. Open Access terms of the Creative Commons Attribution 4.0 International License (http://creativecommons.org/licenses/by/4.0/) apply. The license permits unrestricted use, distribution, and reproduction in any medium, on the condition that users give exact credit to the original author(s) and the source, provide a link to the Creative Commons license, and indicate if they made any changes. 
mathematics identity formation (Darragh, 2013). Yet an increasing body of research has delved into ways of intervening to promote adaptive student identity in mathematics classrooms - an identity that can change to suit different conditions or requirements in various roles.

The goal of this article is to help readers, researchers, and educators have a better understanding of identity and answer the question of how do educators influence identity in mathematics classrooms? To do so, a review of literature that explicitly invokes identity as a construct in intervention studies that focus on student's self-perceptions, goals, beliefs, and actions in mathematics classrooms is presented. The opening is a brief discussion on identity in the mathematics classroom, including the history of the identity concept and various perspectives on identity. Next, a comprehensive overview of the various perspectives on identity is presented. Then attention is devoted to research on identity interventions in mathematics classrooms stemming from the various perspectives on identity. Finally, a summary relative to theory, methodology, and pedagogy and discussion of future directions related to intervening with identity in mathematics classrooms is offered.

\section{IDENTITY PERSPECTIVES AND IDENTITY IN THE MATHEMATICS CLASSROOM}

Scholars have had a long-standing curiosity in the connections between education and identity (Kaplan \& Flum, 2012). While researchers have defined and theorized identity in many ways, the modern usage of the term has been attributed primarily to the work of Erik Erikson. Erikson's (1963, 1968, 1982) psychosocial perspective on identity draws on psychoanalytical notions of ego development, but with a strong emphasis on the essential role of the social-cultural environment in this process. His conceptualization of identity involves both conscious and unconscious life-long strivings for an integrated sense of one's individuality and social belonging to one's community in ways that promote coherence and continuity (Erikson; 1968; Kroger, 2007). Soon after Erikson coined the term, however, scholars from other psychological traditions have adopted it to refer to slightly different self-related phenomena (Gleeson, 1983), including identification with particular social roles and their societal scripts (Stryker, 1968), group membership and its psychological consequences (Tajfel \& Turner, 1986), and social-cultural dynamics of positioning and its cultural consequences (Holland et al., 1998). This has led to a multitude of definitions that reflect somewhat different emphases. For example, Waterman (1984) defined identity as "a clearly delineated self-definition comprised of those goals, values, and beliefs to which the person is unequivocally committed" (p. 331); Cain (1991) defined it as "the way a person understands and views himself, and is viewed by others, a perception of self that is fairly constant..." (p. 210); and Gee (2000) defined it as "being recognized as a certain 'kind of person,' in a given context" (p. 99). Also, one person can, and often does, hold multiple identities (e.g. mother, wife, professor [researcher, teacher, mathematician], daughter, etc.; Gergen, 1992) often depending on his or her current role (Kaplan \& Garner, 2017).

The different definitions reflect various perspectives on whether identity is stable or malleable, individual or collective, situation-specific or cross-contextual, and studied best with quantitative or qualitative methods (Vignoles et al., 2011). Perhaps, the main perspectives to generate sizable bodies of literature on identity have been the psychosocial, sociocultural, social-cognitive, situative, and post-modern or critical perspectives (Kroger, 2007). In the next section, the main tenets of each perspective are reviewed, in addition to a recent integrative perspective that conceptualizes identity as a complex dynamic system (Kaplan \& Garner, 2017). After is a review on the application of these different perspectives to research and interventions in the domain of mathematics education and present findings from new research that follows the integrative perspective mentioned above.

\section{The Psychosocial Perspective}

The psychosocial perspective on identity draws on Erikson's theory and views identity as the person's comprehensive psychological structure that develops throughout life. It describes identity formation as a process involving three facets - identification, exploration, and commitment. Identification involves the uncritical adoption of the self of significant others' characteristics, ideas, and attitudes (Kroger, 2007). These identifications may be rigid, archaic, underdeveloped, not fully integrated into one's identity structure meaning the person has not fully committed to the identification -, and thus, may hinder adaptable coping with changing circumstances. Therefore, Erikson considered mature identity formation to begin "where the usefulness of identification ends" (Erikson, 1968, p. 159); that is, it begins with the questioning of these identifications and the exploration of these and others. In identity exploration, the person gathers information, questions, experiments, and reflects on beliefs, abilities, values, goals, and roles. Exploration is "the work" of 
identity and a key process of identity formation (Grotevant, 1987). Through identity exploration, the person examines and can eventually form a commitment to beliefs, values, goals, and social roles that serve to define who he or she is in the world. Desirably, the process of identity exploration involves the consolidation and integration of such commitments into a coherent sense of self (Erikson, 1968).

Marcia (1993) built on Erikson's perspective to investigate individual differences in identity formation and outlined general styles: diffused, foreclosed, moratorium, and achieved. Other researchers have identified similar breakdowns as diffused, conferred, and self-constructed based on Marcia's work (Flum \& Blustien, 2000). The diffused style of identity formation refers to having low levels of commitments to social roles, little interest in identity issues, and a lack of engagement in self-exploration. Individuals operating within a conferred style also do not engage in an exploration of convictions different from their own but do commit to identifications assigned by significant others. Self-constructed individuals have coherent commitments that they made after exploring alternatives.

Psychosocial research on identity formation indicates that identity exploration is associated with many positive indicators of well-being such as high self-esteem, emotional and academic autonomy, and tolerance of others, openness to experience and intellectual curiosity, a sense of agency, problem-oriented coping skills, and the absence of test anxiety (Berzonsky, 1989; Berzonsky \& Sullivan, 1992; Berzonsky et al., 2003). In contrast, a lack of exploration has been associated with ego closure, inflexible identities, and a tendency to overuse defenses (Berzonsky at al., 2003; Kaplan et al., 2014; Marcia, 1993). Because identity exploration is a key component of self-created identities-a process that is intentional and self-directed-it is associated with a feeling of autonomy, agency, and self-determination (Flum \& Blustein, 2000; Flum \& Kaplan, 2006; Ryan \& Deci, 2000).

\section{The Sociocultural Perspective}

While the psychosocial perspective has often emphasized individual differences and development (e.g., Marcia, 1993), the sociocultural perspective on identity adds an emphasis on the context. In the sociocultural perspective (see Cobb, 1994), students' identities are constructed and enacted through their social participation in cultural activities - for example, their mathematics identities are constructed about the social roles and cultural notions regarding what mathematics is (for) in their participation in activities within mathematics classrooms. In the sociocultural view, a student's performance in the mathematics classroom is the enactment of the student's mathematical identity. From this perspective, learning mathematics and forming a mathematics identity are inseparable, as learning constitutes a process of being socialized into "communities of practice" and "entails becoming a certain kind of person in the world" (Horn, 2008, p. 204). Wenger (1998) describes this process as follows:

Because learning transforms who we are and what we can do, it is an experience of identity. It is not just an accumulation of skills and information, but a process of becoming - to become a certain person or, conversely, to avoid becoming a certain person. Even the learning that we do entirely by ourselves eventually contributes to making us into a specific kind of person. We accumulate skills and information, not in the abstract as ends in themselves, but in the service of an identity (p. 215).

Thus, within the sociocultural perspective, learning is conceptualized not as knowledge acquisition but as identity formation (Boaler \& Greeno, 2000). Therefore, mathematics education research on the development of student mathematics identity from a sociocultural perspective has focused on inclusion within communities of learners of mathematics (Hannula et al., 2016).

Holland and Lachicotte (2007) portray the sociocultural and psychosocial perspectives on identity as oriented toward different phenomena. While a psychosocial identity "is overarching... and weaves together an individual's answers to questions about who he or she is as a member of the cultural and social group(s) that make up his or her society," the sociocultural perspective on identity reflects the "sense of oneself as a participant in the social roles and positions defined by a specific, historically constituted set of social activities" (p. 104). Recently, researchers have pointed to the intersections and complementarity between the sociocultural and psychosocial perspectives on identity, highlighting their joint contribution to understanding the role of identity in students' engagement, learning, and development (e.g., Kaplan et al., 2014; Ryu \& Lombardi, 2015). 


\section{Social-Cognitive Perspectives}

Differently from both the psychosocial and the sociocultural perspectives, the social-cognitive perspective on identity - more frequently referred to as "self"- - highlights the cognitive structures that organize selfrelated knowledge. William James (1890) was one of the initial researchers to conceptualize the self as reflecting both a cognitive structure and identity content and how the social context influences who one is in each moment. More recently, social cognitive scholars have generated various models of identity that elaborate on certain social-cognitive processes involved in the development of people's self-schemas.

Oyserman and colleagues (Oyserman, 2007, 2009; Oyserman \& James, 2009), for example, incorporated insights from social cognition research to conceive the self as comprising a set of identities. In their identitybased motivation model, they use self-concepts to conceptualize how identity content in working memory influences feelings and actions. Those self-concepts in working memory are influenced by features of the situation, and by experiences that lead to revising and altering them. Oyserman and colleagues also suggest that the alignment between the content of the self-schema and the actions called for in the immediate context led to higher motivation.

In a different social-cognitive model of identity, Eccles (2009) described how personal ("Me" self) and collective ("We" self) identities develop over time and the impact these identities may have on motivating action. She describes "Me" self as "personal identities are those aspects of one's identity that serve the psychological function of making one feel unique" (p. 78) and "We" self as "personally valued parts of the self that serve to strengthen one's ties to highly valued social groups and relationships" (p.78). Specifically, Eccles's model emphasizes the role of people's self-competence beliefs and perceived task values-the subjective meaning of the task to their identity-as underlying their decisions to engage in the task. Task values include the perception that a task is interesting, useful for the achievement of personal goals, and affirming of an identifying characteristic such as a worldview or a self-perception. In a longitudinal study, Wigfield and colleagues (1997) found that self-related beliefs about competence and relative, subjective task value predicted important life choices for adolescents. The findings suggest that individuals select to engage in tasks based on prior social experiences and interpretations of experiences as reflecting their identities. These decisions and the resultant new experiences further inform notions of self in a reciprocal process that is influenced by cultural notions of self. As individuals develop, they become more adept at selecting social contexts that permit the intentional choice of new experiences that shape their identities in desired ways. This developmental process seems consistent with the Eriksonian (1968) psychosocial developmental cycle of identification, exploration, and commitment. It, too, highlights how social interactions can influence notions of whom one is while emphasizing the possibilities for agentic selection of subsequent experiences that influence whom one becomes that are informed by beliefs about whom one wants to be. However, unlike the psychosocial perspective, which involves unconscious processes and the life-span development of the ego, social cognitive perspectives on identity highlight cognitive-emotional self-knowledge structures and focus on situations and contextual influences on self and action.

\section{Situated Perspectives}

A fourth approach portrays identity as situative and pulls from both the social-cognitive and the sociocultural perspectives, this approach highlights how identities and their relations to action are constructed anew in each situation. Hand and Gresalfi (2015) state, "situative analyses enable researchers to capture the dynamic interplay of individuals and resources, thus accounting for aspects of structure and agency in all social interaction" (p. 201). Nolen and colleagues, for example, followed a situative perspective for studying preservice teachers and how or why preservice teachers learn (or fail to learn) instructional practices during teacher education programs. This situative approach (building on the work of others, e.g., Greeno, 2006; Lave \& Wenger, 1991) views identity, motivation, and learning as affiliated processes. Horn, Nolen, Ward, and Campbell (2008) bring Holland et al.'s (1998) sociocultural concept of "figured worlds"-culturally-constructed meanings that position people in relational roles and define expectations of their goals, emotions, and behavior - to situations. They discuss how individuals form identities through the situations within which they occupy social roles. A preservice teacher's identity as a student in classroom situations shapes the way he or she engages in coursework during a teacher education program. Later, as the person makes the transition into teaching, new situations and roles shape the construction of his or her identity as a teacher. Horn et al.'s findings indicated that preservice teachers often enter teaching programs with certain beliefs and identities, but teacher education programs and the situations they create can help modify or shift these identities. Through participation in various situated figured worlds (e.g., courses in teacher education 
programs or fieldwork), preservice teachers can negotiate identities, begin to understand themselves as teachers and change their motivation and learning agendas.

\section{Postmodern/Critical Perspectives}

In correspondence with the situative perspective, the postmodern perspective views identity as a relational and transitory psychological phenomenon. Gergen (1992), one of the proponents of identity from a postmodern perspective, believes that postmodern culture removes the category of self. Instead, the view is that the self is a relational construct that is influenced by culture. He wrote, "For everything that we 'know to be true' about ourselves, other voices within respond with doubt and even derision" (Gergen, 1992, p. 228). Gergen's postmodern perspective holds that in the contemporary ever-changing, technologically saturated society, people play multiple "selves," and it is impossible to know which of these selves the one true self is. The constantly changing context produces a constantly changing self. This idea stands in contrast with the psychosocial perspective that views identity as based on "sameness and continuity" (e.g., Rattansi \& Phoenix, 2005; Schachter, 2005). From the postmodern perspective, commitment and stability limit personal freedom (Gergen, 1991).

Aligned with the highly constructed postmodern perspective on identity, several scholars built on Paolo Freire's (1970) critical pedagogy to argue that identities do not have any essential existence and are constructed through power structures that subjugate the powerless into assuming disenfranchised identities (e.g., Giroux, 1997; McLaren, 2002). The critical perspective on identity argues for a liberatory project that aims to help students and teachers be aware of the dynamics of power in social reality and assume agency in constructing identities that are based on their values.

\section{Dynamic Systems/Complexity Perspectives}

A more recent perspective on identity attempts to integrate insights from the various established perspectives into a unified model. Building on assumptions of complexity science - the study of a system several scholars (Kaplan \& Garner, 2017; Kunnen \& van Geert, 2012) view identity formation and development as a complex system characterized by the interdependence of components, non-reductionism, non-linearity, non-determinism, and context-dependence. Kaplan and Garner (2017) presented the Dynamic Systems Model of Role Identity (DSMRI) as a framework that conceptualizes identity as a hierarchical complex dynamic system of role identities, with each role identity comprising four interdependent and ever-emerging components - ontological and epistemological beliefs, purposes and goals, self-perceptions and definitions, and perceived action possibilities. This dynamic system continuously emerges in nonlinear ways within sociocultural situations, through relational processes, with cultural norms as well as unconscious personal dispositions serving as control parameters for its emergence.

\section{Summary of Theoretical Perspectives}

Although differences exist among the various perspectives on identity, there are similarities. These include the involvement of a combined configuration of personal attributes, values, and goals, agency in the selfconstruction of this combined configuration, the importance of the social-cultural environment on the selfconstruction of identity, and the idea that an individual is more adjusted when an identity structure is more unified and consistent (Kaplan \& Flum, 2010). Moreover, many definitions have in common the idea that identity can change from setting to setting or can be unstable at any given moment. This ability to change makes identity a relational phenomenon as opposed to a fixed attribute (Oruç, 2012).

When looking at research on identity formation specifically within mathematics education, the literature has generally taken a sociocultural perspective (Hannula et al., 2016) and has focused on processes of negotiation of identities within discourses that position students and teachers in social-cultural roles (e.g., a math person/not a math person, a fast/slow learner, a reform/traditional teacher). However, research and interventions on identity in mathematics classrooms from each of the identity perspectives exist. To demonstrate this, sample interventions from each perspective are reviewed before discussing two new studies and their findings. This sample literature is by no means a comprehensive review of identity intervention literature. Rather, the researchers selected studies that they feel demonstrate how to intervene in identity using each of the perspectives above as a theoretical perspective. 


\section{INTERVENTIONS IN IDENTITY IN MATHEMATICS CLASSROOMS}

This section provides a summary of studies that implement interventions on student's self-perceptions, goals, beliefs, and actions in mathematics classrooms that explicitly invoke identity as a construct. The studies range from middle school mathematics classrooms to college mathematics classrooms, with some focusing on teacher education, to demonstrate a variety of methods and timing in intervening on identity in relation to mathematics. The scholarly work is broken into categories stemming from each perspective on identity. Under each perspective is one example of an intervention or a collection of intervention-style studies from a group of identity researchers.

\section{An Intervention from the Psychosocial Perspective}

Drawing on the work and definitions of Erikson and Marcia - thus following the psychosocial perspective and focusing on identity exploration, Sinai and colleagues (2012) intervened on identity in a mathematics middle school classroom using a designed based research method. In collaboration with the classroom teacher, they implemented the PRESS (acronym defined below) model to promote students' identity exploration around mathematical concepts within the middle school mathematics curriculum. The PRESS model consists of four principles that promote identity exploration: Promoting Relevance, triggering Exploration, providing a sense of Safety, and Scaffolding exploration (Heffernan et al., 2017). The researcher and teacher discussed identity exploration, how to facilitate exploration, and which mathematics concepts to use for identity exploration lessons and tasks. They then designed a lesson that both focused on one of the selected mathematics topics and incorporated the four PRESS principles. Data was collected from the implemented lesson and analyzed before the next lesson was designed and implemented so that the results of each prior lesson could help in the design of subsequent lessons. The 33 middle school math students were all part of an Israeli school's highly competitive pre-med/veterinary track mathematics class. Because of this competitive nature, students had a strong concentration on grades and high ability in relation to peers and thus had more performance-aligned goals.

At the beginning of the year, during an introductory lesson, the teacher explained to students that the class would have a focus on integrating mathematics with their identities. Content-based lessons then followed that included the activities applying the PRESS framework to central mathematics concepts in hopes of facilitating identity exploration. The framework was applied in lessons on triangles, functions, and trigonometry. One activity included having students identify right triangles in their homes and to provide photographs, drawings, or verbal descriptions to share with the class. After, the teacher taught several lessons on attributes of right triangles. In another lesson, focusing on the central mathematical concept of functions, the teacher asked students to generate examples of function relationships in their own lives. They created graphs of the relationship between the time they spent on homework and the time left to spend on other activities, and they spontaneously considered a students' phone ringing during class and the teachers' anger as a function relationship. In a lesson on trigonometry, the teacher asked students to draw a right triangle in which one side represented the student, and the others represented two meaningful people in their lives. The angles between the sides were to represent the level of closeness felt with these people. The class then discussed sine, cosine, and tangent in terms of relationships in the personal as well as the mathematical senses of the term. A final activity involved having students consider the school as a triangle. The sides of the triangle were to depict different characteristics, and the students were to position themselves relative to the centroid of the triangle.

Following each of these lessons, the students reflected on their experiences in journal writing. The activities in this study were designed to promote the relevance of the mathematical concepts to students' lives and trigger identity exploration. The teacher provided a sense of safety for students by validating various presentations of students' results and creating a respectful and welcoming classroom for students to share their experiences. Using questions during the activities and prompts for the reflective journal writing, the teacher was able to scaffold student identity exploration. The analysis of data including observations, student assignments, student reflective writing journals, and focus groups suggested that the intervention promoted engagement and motivation with the mathematics concepts. Many of the students also underwent identity exploration. While some of the more grade-conscious students were more apt to resist the idea of identity exploration, most of the mathematics students experienced the learning as relevant, and students generally reported increased understanding of the mathematics content as a result of (as one student put it) "...learning new material in math by thinking about ourselves" (Sinai et al, 2013, p. 16). However, only a few students engaged in full-fledged identity exploration throughout the intervention. 


\section{Interventions from the Social-Cognitive Perspective}

Oyserman and colleagues conducted several research studies involving interventions on student identity focusing on racial-ethnic self-schemas (RES) - organized generalizations about one's self in relation to raceethnicity. Oyserman et al. (2003) used an experimental manipulation by making RES salient in two of three separate studies involving American Indian and Arab-Palestinian Israeli junior and high school students. The goal of the experimental manipulation was to assess the causality of the positive effect of RES that the researchers predicted. Their rationale for manipulating RES salience stems from social cognition research. Social-cognitive research suggests that salient knowledge, rather than all relevant knowledge, influences behavior when a person in making a behavioral decision. (Bargh \& Chartrand, 1999; Higgins, 1996, referenced in Oyserman et al., 2013). Using this perspective, the researchers hypothesized that RES would influence a student's academic behavior only when it is recalled. In the study, participants fell into three categories of RES: RES aschematic (meaning they do not have a RES), RES "in-group only" (meaning only in-group references and not larger society references are included in RES), and both "in-group" and larger society RES.

In the first of the two interventions, American Indian junior high and high school students were asked the question of what being American Indian meant to them. For the high-salience condition, students were asked this question before working on a mathematical task, and for the low-salience condition, students were asked this question after completing the mathematical task. The mathematical task that students had to complete involved using the numbers 2,3 , and 7 to obtain the number 36 through addition, subtraction, multiplication, or division without a limitation of the number of times each number could be used. The goal was to obtain 36 in as many ways as possible. This task was not something previously taught to students. The analysis was based on the number of attempts each student made to obtain thirty-six.

The researchers predicted that students with both in-group and larger society RES would be shielded from a negative stereotype effect and social representations of their associated in-group and persist more during the mathematical task when in the high-salience condition. Controlling for both gender and school grades, a significant main effect of RES was found. Students with both in-group and larger society RES had a higher academic persistence than students with only in-group RES or aschematic RES. When separating based on high-salience condition and low-salience condition, a significant contrast appeared between RES groups when excluding the low-salience condition, but not when excluding the high-salience condition, indicating that there are significant effects from making RES salient.

In the second intervention, Arab-Palestinian Israeli high school students participated in the same experimental manipulation involving RES. Students were again either in a high-salience condition and asked to describe their RES before completing a mathematical task, or in a low-salience condition and asked to complete the mathematical task before describing their RES. Once more, those students who were RES aschematic and RES in-group only reduced effort during the mathematical task when their RES was made salient, and those who were both in-group and larger society RES did not reduce effort. Because the second intervention had a much larger sample size than the first intervention ( $N=524 \mathrm{vs} . N=65$, respectively), additional analysis was conducted, and results showed that older teens were more likely to be minority RES schematic (meaning being a member of an in-group and fighting to overcome difficulties to achieve larger societal resources) than RES aschematic or both in-group and larger society RES schematic.

The results of Oyserman et al.'s (2013) study showed the motivational consequences in the result of situationally prompting RES. When students were reminded of their RES, disengagement in a task followed when students were RES aschematic or RES in-group only. This study followed a similar study by Oyserman, Grant, and Ager (1995) that examined the effect of asking students about being African American on a mathematical task completed immediately after. Depending on what student responses consisted of, the performance was either hindered or improved. If a student expressed a connection to the African American community and felt that African Americans engage academically, he or she did better on the mathematics task. If the student did not express a combination of these thoughts/feelings, the student was less likely to perform well on or attempt the task. Again, the findings indicate that identities only influence behavior or performance when on a student's mind at the time.

In another study with low-income middle school students, Elmore and Oyserman (2012) examine the effects of gender identity on academic success when performing a mathematical task. Students were asked to answer a question regarding the coming year, complete a math task, and answer a question about future aspirations after analyzing one of four Census graphs. The graphs consisted of (1) comparing gender for earnings (men earn more than women do), (2) comparing gender for graduation rates (women have a higher 
high school graduation rate), (3) information pertaining to earnings without gender breakdown, and (4) information pertaining to graduation rates without gender breakdown. Results showed that girls performed better than boys, except for the boys who were shown the first graph (men earn more than women). Boys in this group put more effort into the math task, stated more identities that are possible for the coming year and ways to attain the identities, and stated more career options for their futures. This study again demonstrates that identity influences action, but the context in which the identity is constructed is an important factor in that action.

\section{Interventions from the Social-Cultural Perspective}

Contemporary research on the negotiation of academic identities in mathematics classrooms is generally presumed to occur within educational sociocultural settings that offer normative academic roles that students may either identify with or resist (Cobb et al., 2009). Research helps to integrate an understanding of mathematics identity structures, contents, and processes. Cobb and colleagues (2009) introduce an interpretive scheme for analyzing normative mathematics identities within classrooms and the extent to which individual students identify with, resist, or merely comply with these mathematical classroom obligations and otherwise negotiate what it means to know and do mathematics in particular mathematics classrooms. In their study that involved 11 eighth-grade students, the students participated in two mathematics classes. The first class was taught at the end of the day by a member of the research team and followed a design experiment that focused on statistical data analysis. The other was an algebra class taught by the regular middle school mathematics teacher. The teacher held the authority during the algebra class, and students held the obligations of listing explanations, replicating steps, and occasionally explaining their work for completed homework questions. The design experiment had joint authority between the instructor and students, and students were obligated to explain how they used the computer system for data analysis and their reasons for creating certain displays of the data.

The analysis focused on both the normative and personal identities developed in the classes. By revealing the classroom norms regarding mathematical obligations, the researchers found that many students adopt these norms. Obligations for others become obligations for oneself, and students' mathematical identities generally become consistent with the micro-culture established in the mathematics classroom and its normative mathematics identity. Other students comply without identifying with the role of effective mathematics student as co-constructed within the classroom context. Still, others resist classroom norms and may have a different view of what those norms are than cooperating students have. Cobb, Gresalfi, and Hodge take an integrative view of contents and processes but not structures of mathematics identities.

Boaler and Greeno (Boaler, 1997; Boaler \& Greeno, 2000) employ a sociocultural perspective focused on describing the ways mathematics identities develop in relation to the classroom culture. Boaler (1997) investigated two schools in the United Kingdom with similar populations of students in terms of ethnicity, social class, and prior mathematical attainment. She found that in classrooms using reform-based methods, students talked more positively about mathematics, expressed intentions to pursue mathematics-related studies in higher education, and developed more flexible forms of knowledge. In classrooms taught with traditional approaches, students tended to reject mathematics and expressed negative feelings towards the subject.

Boaler and Greeno (2000) replicated these findings in a study of Advanced Placement (AP) Calculus classrooms in eight California schools. Students in reform classrooms described their participation in active terms and did not perceive the same dissonance between the identities that they were developing and their perceptions of whom they were expected to be in the mathematics classroom. Successful mathematics students in the traditional classes were rejecting mathematics to pursue opportunities for expression, interpretation, and human agency that they did not perceive as offered in mathematics class. These students chose not to continue to study mathematics because of an experienced incongruity between how they view themselves now, whom they would like to become, and whom they are expected to be in their mathematics classrooms. In the traditional classrooms, knowledge had been presented to the students, and the students were expected to embrace teacher and textbook demonstrations. The mathematical authority was vested in sources external to the students. "The students all talked about the kinds of person they wanted to be-people who used their own ideas, engaged in social interaction and exercised their own freedom and thought" (p. 44), but some of the students felt that they could not be such a person in mathematics class. The identities they perceived to be desirable in their calculus classrooms conflicted with the identities they were forming in other aspects of their 
lives. The negative reaction to mathematics experienced by some of these students could be explained by their reaction to being positioned as "received knowers" (p. 44) with no room for personal interpretation or agency.

Finally, Russo and Russo (2019) looked at how including an inquiry-based mathematics unit that centered on teachers' interests impacted student learning and motivation. In the study, five fifth and sixth-grade teachers were asked to design inquiry-based lessons centered on topics of personal interest. The lessons included learning mathematics through basketball, robotics, space, dance, and zoos. While not explicitly studying mathematics identity of students, including an intervention that focused on "Teacher Interest-Let Inquiry" led to many students' intrinsic motivation increasing and students valuing mathematics more due to the ability to connect to mathematics on more of a personal level. This particular study is interesting because interventions rarely look at concurrently increasing teacher and student interest and motivation by making mathematics more relevant to the lives of both.

\section{Interventions from the Situated Perspective}

While studies that explicitly follow the situated perspective, focus on identity, and attempt to intervene on mathematics identity (performing some task outside of the normal classroom structure) appear to not exist yet in peer-reviewed research, researchers recently have been looking at models that follow the perspective and specifically intervene on student identity. For example, Gresalfi and Hand (2019) propose a model that draws on the situative theory of identity and considers the alignment of classroom norms, frames, and narratives in identity development. While they themselves do not perform an intervention on mathematics identity, they pull from other interventions that focus on either norms, frames, or narratives as a way of aligning resources available for identity development. Thus, researchers have begun to conceptualize the idea of intervening using the situative perspective and have begun to call for other researchers to do so as well.

\section{Interventions from the Postmodern/Critical Perspective}

The work of Martin, followed by others (e.g., Berry, 2005; McGee \& Martin, 2011; Moody, 2004) focuses on the influence of African American students' racial identities in shaping their identities as students in mathematics classrooms, including their self-perceptions as a mathematics student and their goals to persist in learning the subject. Martin (2000) examined mathematics identity and participants' definitions of "being African American" while in a mathematics learning context and found that the students could not separate their racial identities and their experiences learning mathematics. Similarly, Moody (2004) interviewed two African American women who were working towards mathematics-related college degrees and found a close intertwining of racial identity with mathematics identity. Both women reported perceiving racism in mathematics classes. Berry's (2005) study with African American middle school boys also found that the students were dealing with racism while in mathematics classrooms. Many of the researchers focusing on the connection between racial identity and mathematics identity use critical race theory as a theoretical perspective in understanding the role of racism in academic experiences. Critical race theory views racism as permanent fixtures in society and places a strong emphasis on the voice of Black and minority ethnic groups (Ladson-Billings, 1998).

McGee (2009) found that when a Black college student was one of few Black students or the only Black student in a class or program, he or she faced and successfully negotiated racial stereotypes, lowered expectations, and racist ideologies in mathematics and science classrooms.

In their 2011 study, Martin and McGee looked at the responses and managing of stereotypes for 23 highachieving Black students in competitive mathematics and engineering majors. Through the coding and analysis of semi-structures, life-story interviews, six themes were revealed for students' responses to stereotypes: (1) attempting to prove a stereotype wrong, (2) always being on point, (3) critical perceptions and attributions of behavior, (4) cultural code-switching and frontin', (5) excelling to be perceived as smart, and (6) constructing self-directed and self-determined identities. The findings reveal that many of the participants, and likely other academically successful minority students, engage in stereotype management. That is, the students exercise agency to achieve success in mathematics and science courses rather than internalize stereotypes, bias, and racism and allow the internalization to lessen performance and achievement. "The shift from proving stereotypes wrong to building a more self-defined identity in which managing stereotypes plays a minimal role and toll demonstrates the power of identity-related coping mechanisms in reducing the toxic and educational costs of racial stereotypes" (p. 1379).

While Martin and McGee's study was a non-experimental condition, and the researchers warn that interventions often do not question the everyday racial microaggressions that students face, their studies help 
to understand the idea of stereotype management and its implications on maintaining strong racial identities while excelling in mathematics classes and forming strong disciplinary identities. The researchers stress the need for additional studies that focus on helping minority students manage stereotypes and positively coconstruct identities, including racial identities and mathematical identities.

\section{Interventions from the Complexity Perspective}

Following the framework of the Dynamic Systems Model of Role Identity (DSMRI) and viewing identity as a hierarchical complex dynamic system of role identities comprising of ontological and epistemological beliefs, purposes and goals, self-perceptions and definitions, and perceived action possibilities, the researchers conducted two separate studies that intervened on students' identities in relation to mathematics. The studies below connect two doctoral dissertation findings on an intervention conducted in a teacher education program and an intervention conducted in a high school classroom. Together, these studies demonstrate identity intervention from the complexity perspective.

It is well known, and research has shown, that early childhood preservice teachers have high mathematics anxiety that impedes success in mathematics courses (Beilock et al., 2010); however, social science and humanities majors also have high levels of mathematics anxiety (Hembree, 1990), indicating that many preservice teachers in non-mathematics secondary concentrations are also likely to have anxiety towards mathematics. Thus, interventions that promote identity exploration in relation to mathematics on both early childhood and non-mathematics secondary students is warranted. In a study conducted on preservice teachers' mathematics student identity, sixteen out of a total of 24 students enrolled in a mathematics course specifically designed for education majors, were majoring in either early childhood education or a dual early childhood and special education major. The remaining eight students were secondary education students with a concentration in either English, social studies, or world languages. Many students in this study were anxious about mathematics. Also, the secondary education preservice teachers were not as motivated as the early childhood preservice teachers in learning mathematics and had a larger focus on grades.

Like Sinai and colleagues, the researchers incorporated the principles from the PRESS model with various mathematical identity exploration tasks designed in cycles. The main mathematical concepts used included linear equations and functions, transformations of functions, quadratic equations and functions, and systems of equations, all core concepts in the College Algebra course. The linear equations task involved students creating two graphs, with the first graph representing the student's opinion on the relationship between mathematical knowledge (x-axis) and success in teaching (y-axis) and the second graph representing the student's opinion on the relationship between liking mathematics (x-axis) and success in teaching mathematics (y-axis). The function transformation task had students create both an independent and dependent variable for a given graph and discuss what would cause a negative horizontal shift and a positive horizontal shift to occur. In a second problem, students were asked to create a graph for two new variables, shift the graph vertically in both a positive and negative direction, and describe what would cause these shifts to occur. After a lesson on quadratic functions, students completed a third identity exploration task that involved creating a self-relevant example of a quadratic function and explaining the meaning of the minimum and maximum value of that function. In the final task, students worked in pairs during class to create a system of linear equations with variables that were self-relevant to both students. Each student created one linear equation and graph using the variables, and then the students met with their partners to put both equations and graphs together to form a system and discuss the meaning of the intersection point (or solution) of the system. These activities guided students to explore both their student identity in relation to mathematics and their future teacher identity.

The intervention promoted relevance by explicitly prompting students to create examples that they felt were self-relevant using the mathematical content. Students were encouraged to reflect on the created functions and graphs in their meaning to the self to trigger exploration. Students' sense of safety was maintained through working with peers, asking for volunteers during discussions, and having both the instructor and researcher available to ask questions. Finally, identity exploration was scaffolded through worked examples, discussions, and engaging students in reflective writing.

Data included pre- and post- Likert-scale surveys (measuring anxiety, mathematical value, goals, selfperceptions, beliefs, and self-regulation strategies), observations, interview transcriptions, the four identity exploration tasks, students' weekly reflective writings, and six identity worksheets. The identity worksheets and reflective writings were based on the DSMRI, in that students were asked to identify aspects (belief, goal, self-perception, and action) of their role identities as mathematics students and/or future teacher self. Analysis 
of the data showed that the various activities promoted identity exploration and change in self-perceptions and attitudes regarding mathematics for most students. Some students engaged in mathematics identity exploration and reflection during the pre-survey conducted during the initial meeting, while other students found the identity exploration tasks helpful in increasing their perceived self-relevance of the mathematics content. Some students found the weekly reflective writings to be the most beneficial in scaffolding perceived self-relevance of the mathematical content and exploring its meaning to their current student identities and their future teacher identities. Some of the preservice teachers found a combination of the activities and reflective writing to be useful. Still, a few preservice teachers resisted identity exploration. This range of responses is like the findings of Sinai and colleagues. Heffernan and Newton (2019) describe specific cases of early childhood students' experiences in more detail.

The data suggest that the various aspects of the study promoted identity explorations more effectively for the early childhood preservice teachers than for the secondary education preservice teachers. This is attributed to there likely being a higher perception of relevance to an early childhood education degree and teaching career than to a secondary education degree and teaching career. Moreover, early childhood preservice teachers who held negative initial self-perceptions and attitudes towards mathematics engaged in more identity exploration than the early childhood preservice teachers who held initial positive self-perceptions and attitudes towards mathematics. The various activities included in the intervention helped many of the preservice teachers see the importance of learning the mathematical course content and the relevance of the content to their future teaching endeavors.

Similarly, the PRESS model was used in another study with to promote high school Algebra 2 students' identity exploration, motivation, and achievement. Four core algebra concepts - exponential functions, arithmetic and geometric sequences, quadratic functions, and linear functions - were selected for the intervention. After a lesson on one of these concepts, students completed an individual in-class assignment, which varied according to the group to which they had been assigned. Using random assignment of subjects to treatments within six Algebra 2 classrooms of three teachers, the researchers compared the motivation and achievement of students undergoing the program designed to trigger identity exploration around mathematics concepts (the Exploration Group) with that of students who (1) received the instruction that had been normative in the school ("business-as-usual," "Problems" group), and (2) who received an alternative pedagogical program that resembled the activities in the target program but did not involve the identity exploration component ("Summary" group).

Each reflective writing task for the Exploration Group consisted of three parts. The first was a prompt used to activate consideration of self-aspects in relation to the mathematics lesson of the day. For example, in part 1 of the survey on exponential functions, students were asked, "How do the ideas of exponential functions relate to something meaningful to me and my life?" The second part was intended to encourage students to examine prior identifications by confronting students with their possibly under-examined beliefs, values, goals, and behaviors. An experience of discrepancy may serve as an identity exploration trigger; therefore, this part of the intervention asked students to identify specific mathematics identity components and to examine their coherence. Based on the DSMRI, students were asked to identify aspects of their role identities as mathematics students - a belief, a goal, a value, and an action - that were personally influential during the day's lesson. Then, the students were presented with a computer-generated sentence attempting to logically connect these identity aspects into a coherent statement about their identity. Students were asked to examine the sentence and describe its accuracy and coherence about their views of themselves and the days' lesson as well as to the mathematics student they were in the past and hope to be in the future.

The third part of each task consisted of a series of prompts intended to scaffold students' processing of the mathematics they were learning about themselves. For example, following a lesson on quadratic functions, students were asked to choose an aspect of themselves that has been changing over time since kindergarten in a way that may be represented by a parabola. After sketching a graph of this parabola, students were asked to find the y-intercept and vertex and to explain the significance of these points to their own lives.

The Exploration Group was compared with two control groups. In the Problems Group (business-as-usual), students' assignments included mathematics problems related to the material taught in the lesson that were like problems found in their textbooks. In the Summary Group, students were asked to summarize what they learned in the lesson and make connections to the material they learned in prior lessons. Pre- and post-survey measures allowed for comparing the change in students' motivation, mathematics identities, and experience of the pedagogical program between the pedagogical approaches. 
Findings indicated that identity exploration was positively associated with incremental theory, mastery goals, intrinsic interest, attainment and external utility value, self-efficacy, use of self-regulation strategies, and positive affect. The motivational and mathematics identity measures were also positively associated with final grades. Identity exploration was negatively associated with undesirable measures of motivation and mathematics identity, including entity theory, performance approach and avoidance goals, and negative affect-measures that were also negatively associated with grades. These findings replicated the results of previous research on theories of intelligence (Dweck, 2007; Grant \& Dweck, 2003) and achievement goals (Senko et al., 2011) demonstrating the benefits of having a mastery orientation toward learning mathematics and a belief that mathematics abilities can be improved with effort. Further, they provide support for the notion that an exploratory orientation in these Algebra 2 classes and mathematics classes more broadly is part of an adaptive student mathematics identity, including a motivational profile that is associated with high achievement in mathematics.

While the qualitative analysis examining students' perceptions of the exploration intervention indicated that many students in the Exploration Group perceived the pedagogical program as promoting self-relevance, most students did not successfully engage in mathematics identity exploration in response to the writing prompts. Additionally, students in the Exploration Group did not indicate significantly higher levels of indepth or class-triggered exploration than the control groups. Therefore, it is not surprising that comparisons of the experimental conditions did not yield important differences at post-survey on the outcome measures. Nevertheless, the findings highlight the potential for interventions successfully promoting the processing of mathematics content in relation to self-aspects. The findings from both of our studies demonstrate ways that teachers can help students make self-relevant connections to mathematics concepts that may facilitate learning and form a basis for identity exploration.

\section{CONCLUSION}

Looking at identity through the various perspectives gives researchers several lenses to understanding how to help shift students' mathematics identities in a positive direction. Each perspective lends way to designing and analyzing interventions that focus on identity development and exploration in different ways. With any research, it is important to have a theoretical perspective to guide your analysis. Identity is a concept that is complex, is defined in several different ways, and - as this review displays - can be viewed from many different perspectives, often times making it overwhelming to study. This review can help researchers beginning to look at identity have a better understanding of the various perspectives and decipher which best fits for their own beliefs and studies.

Across perspectives, the studies reviewed demonstrate that mathematics identities motivate action and that mathematics educators can influence students' mathematical identities. Additionally, the findings of Sinai et al. (2013), along with the findings from the complex perspective interventions above, suggest that mathematics teachers who actively facilitate their students' mathematics identity exploration may also be helping their students form positive mathematics identities, develop adaptive motivational profiles, and demonstrate increased learning of mathematics at various levels, ranging from middle school through higher education. As a concept rooted in the psychosocial perspective on identity, exploration is a key identity process that has until lately been essentially overlooked by researchers investigating mathematics identity from a sociocultural perspective. When teachers establish a normative classroom goal structure where students are expected to examine the meaning of mathematics concepts to their emerging senses of self, these studies suggest that students may be more likely to develop adaptive mathematics identities.

Through this display of sample research on interventions promoting identity and/or identity exploration in mathematics classrooms, the researchers hope to help readers, other researchers, and educators understand the various perspectives on identity, understand that identity can be influenced, and learn how researchers and educators have thus far impacted identity in mathematics classrooms. Also, the researchers hope to bring more awareness to the study of identity and identity development to mathematics education. A limitation of this review is that it provides a minimum number of intervention studies. Future research should include a meta-analysis review to look at a wider range of research on identity interventions within the mathematics classroom. Also, the lack of research from the situated identity perspective that explicitly include interventions is another limitation. Identity, including mathematics identity, is a topic that should continue to be researched in education as it has a large potential in impacting student motivation and success in both mathematics and education, regardless of the perspective the research follows. Many of the studies mentioned above stress the need for more research on how educators and the education community can help students positively construct 
and/or re-construct identities, including but not limited to racial, gender, and mathematical identities, thus further warranting the continuation of studying identity in education.

\section{Disclosure statement}

No potential conflict of interest was reported by the authors.

\section{Notes on contributors}

Kayla Heffernan - Department of Mathematics, University of Pittsburgh at Greensburg, 150 Finoli Drive, Greensburg, PA 15601, USA.

Steven Peterson - Haverford High School, 200 Mill Road, Havertown, PA 19083, USA.

Avi Kaplan - Department of Psychological Studies in Education, Temple University, 1301 Cecil B. Moore Avenue, Philadelphia, PA 19122, USA.

Kristie J. Newton - Department of Teaching and Learning, Temple University, 1301 Cecil B. Moore Avenue, Philadelphia, PA 19122, USA.

\section{REFERENCES}

Anderson, R. (2007). Being a mathematics learner: Four faces of identity. The Mathematics Educator, 17(1), $7-14$.

Bargh, J. A., \& Chartrand, T. L. (1999). The unbearable automaticity of being. American Psychologist, 54(7), 462-479. https://doi.org/10.1037//0003-066X.54.7.462

Beilock, S. L., Gunderson, E. A., Ramirez, G., \& Levine, S. C. (2010). Female teachers' math anxiety affects girls' math achievement. Proceedings of the National Academy of Sciences, 107(5), 1860-1863. https://doi.org/10.1073/pnas.0910967107

Berzonsky, M. D. (1989). Identity style conceptualization and measurement. Journal of adolescent research, 4(3), 268-282. https://doi.org/10.1177/074355488943002

Berzonsky, M. D., \& Sullivan, C. (1992). Social-cognitive aspects of identity style need for cognition, experiential openness, and introspection. Journal of Adolescent Research, 7(2), 140-155. https://doi.org/10.1177/074355489272002

Berzonsky, M. D., Macek, P., \& Nurmi, J. (2003). Interrelationships among identity process, content, and structure: A cross-cultural investigation. Journal of Adolescent Research, 18(2), 112-130. https://doi.org/10.1177/0743558402250344

Bishop, J. P. (2012). "She's always been the smart one. I've always been the dumb one": Identities in the mathematics classroom. Journal for Research in Mathematics Education, 43(1), 34-74. https://doi.org/10.5951/jresematheduc.43.1.0034

Black, L. (Ed.), Mendick, H. (Ed.), Solomon, Y. (Ed.). (2009). Mathematical Relationships in Education. New York: Routledge, https://doi.org/10.4324/9780203876114

Blackwell, L. S., Trzesniewski, K. H., \& Dweck, C. S. (2007). Implicit theories of intelligence predict achievement across an adolescent transition: A longitudinal study and an intervention. Child Development, 78(1), 246-263. https://doi.org/10.1111/j.1467-8624.2007.00995.x

Boaler, J. (1997). Experiencing school mathematics: Teaching styles, sex and setting. Buckingham, England: Open University Press.

Boaler, J., \& Greeno, J. G. (2000). Identity, agency, and knowing in mathematics worlds. Multiple perspectives on mathematics teaching and learning, 1, 171-200.

Boaler, J., William, D., \& Zevenbergen, R. (2000, March). The construction of identity in secondary mathematics education. Paper presented at the International Mathematics Education and Society Conference, Montechoro, Portugal.

Cain, C. (1991). Personal stories: Identity acquisition and self-understanding in alcoholics anonymous. Ethos, 19(2), 210-253. https://doi.org/10.1525/eth.1991.19.2.02a00040

Cobb, P. (1994). Where is the mind? Constructivist and sociocultural perspectives on mathematical development. Educational Researcher, 23(7), 13-20. https://doi.org/10.3102/0013189X023007013 
Cobb, P., Gresalfi, M., \& Hodge, L. L. (2009). An interpretive scheme for analyzing the identities that students develop in mathematics classrooms. Journal for Research in Mathematics Education, 40(1), 40-68.

Darragh, L. (2013). Constructing confidence and identities of belonging in mathematics at the transition to secondary school. Research in Mathematics Education, 15(3), 215-229. https://doi.org/10.1080/14794802.2013.803775

Eccles, J. (2009). Who am I and what am I going to do with my life? Personal and collective identities as motivators of action. Educational $\quad$ Psychologist, $\quad 44(2), \quad$ 78-89. https://doi.org/10.1080/00461520902832368

Elmore, K. C., \& Oyserman, D. (2012). If 'we' can succeed, 'I' can too: Identity-based motivation and gender in the classroom. Contemporary educational psychology, 37(3), $176-185$. https://doi.org/10.1016/j.cedpsych.2011.05.003

Erikson, E. H. (1963). Childhood and society (rev. ed.). New York: Norton, 1954, 5-56.

Erikson, E. H. (1968). Identity, youth, and crisis. New York: W. W. Norton.

Erikson, E. H. (1982). The life cycle completed: A review. New York: Norton.

Flum, H., \& Blustein, D. L. (2000). Reinvigorating the study of vocational exploration: framework for research. Journal of Vocational Behavior, 56(3), 380-404. https://doi.org/10.1006/jvbe.2000.1721

Flum, H., \& Kaplan, A. (2006). Exploratory orientation as an educational goal. Educational Psychologist, 41(2), 99-110. https://doi.org/10.1207/s15326985ep4102_3

Freire, P. (1970). Pedagogy of the oppressed. New York: Herder and Herder.

Gee, J. P. (2000). Identity as an analytic lens for research in education. Review of Research in Education, 99125. https://doi.org/10.2307/1167322

Gergen, K. J. (1991). The saturated self: Dilemmas of identity in contemporary life. New York, N.Y: Basic Books.

Gergen, K. (1992) 'Organization Theory in the Postmodern Era'. In M. Reed and M. Hughes (Eds.), Rethinking Organizations (pp. 703-723). London: Sage.

Giroux, H. A. (1997). Pedagogy and the politics of hope: Theory, culture, and schooling: A critical reader. Boulder, CO: Westview Press

Gleeson, D. (1983). Youth training and the search for work. London: Routledge.

Greeno, G. (2005). Learning in Activity. In R. Sawyer (Ed.), The Cambridge Handbook of the Learning Sciences (Cambridge Handbooks in Psychology, pp. 79-96). Cambridge: Cambridge University Press. https://doi.org/10.1017/CBO9780511816833.007

Grotevant, H. D. (1987). Toward a process model of identity formation. Journal of adolescent research, 2(3), 203-222. https://doi.org/10.1177/074355488723003

Guastello, S. J., \& Gregson, R. A. M. (2011). Nonlinear dynamical systems analysis using real data. Boca Raton, FL: CRC Press.

Hand, V., \& Gresalfi, M. (2015). The joint accomplishment of identity. Educational Psychologist: The Relevance of the Situated Perspective in Educational Psychology, 50(3), 190-203. https://doi.org/10.1080/00461520.2015.1075401

Hannula, M. S., Di Martino, P., Pantziara, M., Zhang, Q., Morselli, F., Heyd-Metzuyanim, E., ... Goldin, G. A. (2016). Attitudes, Beliefs, Motivation, and Identity in Mathematics Education. In Attitudes, Beliefs, Motivation and Identity in Mathematics Education (pp. 1-35). Springer International Publishing. https://doi.org/10.1007/978-3-319-32811-9

Heffernan, K., Kaplan, A., Peterson, S., \& Newton, K. J. (2017). Integrating identity formation and subject matter learning: Math concepts as tools for identity exploration. In E. Lyle (Ed.), At the intersection of selves and subject: Exploring the curricular landscape of identity (pp. 53-62). The Netherlands: Sense Publications. https://doi.org/10.1007/978-94-6351-113-1

Heffernan, K. A., \& Newton, K. J. (2019). Exploring mathematics identity: an intervention of early childhood preservice teachers. Journal of Early Childhood Teacher Education, 40(3), 296-324.

Hembree, R. (1990). The nature, effects, and relief of mathematics anxiety. Journal for Research in Mathematics Education, 21(1), 33-46. https://doi.org/10.2307/749455 
Higgins, E. T. (1996). Knowledge activation: Accessibility, applicability, and salience. In E. T. Higgins \& A. W. Kruglanski (Eds.), Social psychology: Handbook of basic principles (pp. 133-168). New York: Guilford Press.

Hill M. L. (2009). Beats, rhymes and classroom life: Hip-hop pedagogy and the politics of identity. New York, NY: Teachers College Press.

Holland, D., \& Lachicotte, W. (2007). Vygotsky, mead, and the new sociocultural studies of identity. The Cambridge Companion to Vygotsky, 101-135.

Horn, I. S. (2008). Turnaround students in high school mathematics: Constructing identities of competence through mathematical worlds. Mathematical Thinking and Learning, 10(3), 201-239. https://doi.org/10.1080/10986060802216177

Holland, D., Skinner, D., Lachicotte Jr, W., \& Cain, C. (1998). Identity in cultural worlds. Cambridge, MA: Harvard University Press.

Horn, I. S., Nolen, S. B., Ward, C., \& Campbell, S. S. (2008). Developing practices in multiple worlds: The role of identity in learning to teach. Teacher Education Quarterly, 35(3), 61-72.

James, W. (1890). The consciousness of self. The principles of psychology, 8.

Kaplan, A., \& Flum, H. (2010). Achievement goal orientations and identity formation styles. Educational Research Review, 5(1), 50-67. https://doi.org/10.1016/j.edurev.2009.06.004

Kaplan, A., \& Flum, H. (2012). Identity formation in educational settings: A critical focus for education in the 21st century. Contemporary Educational Psychology, 37(3), https://doi.org/10.1016/j.cedpsych.2012.01.005

Kaplan, A., \& Garner, J. K. (2017). A complex dynamic systems perspective on identity and its development: The Dynamic Systems Model of Role Identity. Developmental Psychology, 53(11), 2036-2051. https://doi.org/10.1037/dev0000339

Kroger, J. (2007). Identity development: Adolescence through adulthood (2nd ed.). Thousand Oaks, CA: Sage Publications.

Kunnen, S., \& van Geert, P. (2012). A dynamic systems approach to adolescent development. In A dynamic systems approach to adolescent development (pp. 19-30). Psychology Press.

Lave, J., \& Wenger, E. (1991). Situated learning: Legitimate peripheral participation. Cambridge [England]; New York: Cambridge University Press.

Marcia, J. E. (1993). The ego identity status approach to ego identity. In J. E. Marcia, A.S. Waterman, D. R. Matteson, S. L. Archer, \& J. L. Orlofsky (Eds.), Ego identity: A handbook for psychosocial research (pp. 3-21). New York: Springer.

McLaren, P. (2002). Critical pedagogy: A look at the major concepts. In A. Darder et al. (Eds.), The critical pedagogy reader (pp. 69-96). New York and London: Routledge Falmer.

Oruç, N. (2013). Early teacher identity development. Procedia-Social and Behavioral Sciences, 70, 207-212. https://doi.org/10.1016/j.sbspro.2013.01.056

Oyserman, D. (2007). Social identity and self-regulation. Social psychology: Handbook of basic principles, 2(1), 432-453.

Oyserman, D. (2008). Possible selves: Identity-based motivation and school success. Self-processes, learning, and enabling human potential, 269-288.

Oyserman, D., Gant, L., \& Ager, J. (1995). A socially contextualized model of racial identity: Possible selves and school persistence. Journal of Personality and Social Psychology, 69, 1216-1232. https://doi.org/10.1037/0022-3514.69.6.1216

Oyserman, D., \& James, L. (2009). Possible selves: From content to process. In K. D. Markman, W. M. P. Klein, \& J. A. Suhr (Eds.), Handbook of imagination and mental simulation (pp. 373-394). Psychology Press.

Oyserman, D., Kemmelmeier, M., Fryberg, S., Brosh, H., \& Hart-Johnson, T. (2003). Racial-ethnic selfschemas. Social Psychology Quarterly, 66(4), 333-347. https://doi.org/10.2307/1519833

Rattansi, A., \& Phoenix, A. (2005). Rethinking youth identities: Modernist and postmodernist frameworks. Identity, 5(2), 97-123. https://doi.org/10.1207/s1532706xid0502_2

Russo, J. A., \& Russo, T. (2019). Teacher Interest-Led Inquiry: Unlocking Teacher Passion to Enhance Student Learning Experiences in Primary Mathematics. International Electronic Journal of Mathematics Education, 14(3), 701-717. http://doi.org/10.29333/iejme/5843 
Ryan, R. M., \& Deci, E. L. (2000). Self-determination theory and the facilitation of intrinsic motivation, social development, and well-being. American Psychologist, 55(1), 68. http://doi.org/10.1037//0003066X.55.1.68

Ryu, S., \& Lombardi, D. (2015). Coding classroom interactions for collective and individual engagement. Educational Psychologist, 50(1), 70-83. http://doi.org/10.1080/00461520.2014.1001891

Schachter, E.P. (2005). Erikson meets the postmodern: Can classic identity theory rise to the challenge?, Identity, 5(2), 137-160. https://doi.org/10.1207/s1532706xid0502_4

Schachter, E. P., \& Rich, Y. (2011). Identity education: A conceptual framework for educational researchers $\begin{array}{lllll}\text { and } & \text { practitioners. } & \text { Educational }\end{array}$ http://doi.org/10.1080/00461520.2011.614509

Sinai, M., Kaplan, A., \& Flum, H. (2012). Promoting identity exploration within the school curriculum: A design-based study in a junior high literature lesson in Israel. Contemporary Educational Psychology, 37(3), 195-205. http://doi.org/10.1016/j.cedpsych.2012.01.006

Sinai, Elgad, \& Manor (2013). Promoting identity exploration using the math curriculum: A design-based study in a junior high math class in Israel. Paper presented at the annual meeting of the American Educational Research Association, San Francisco, April 2013.

Stryker, S. (1968). Identity Salience and Role Performance: The Relevance of Symbolic Interaction Theory for Family Research. Journal of Marriage and Family, 30(4), 558-564. http://doi.org/10.2307/349494

Tajfel, H., \& Turner, J. C. (2004). The Social Identity Theory of Intergroup Behavior. In J. T. Jost \& J. Sidanius (Eds.), Key readings in social psychology. Political psychology: Key readings (pp. 276-293). Psychology Press. https://doi.org/10.4324/9780203505984-16

Vignoles, V. L., Schwartz, S. J., \& Luyckx, K. (2011). Introduction: Toward an integrative view of identity. In Handbook of identity theory and research (pp. 1-27). Springer, New York, NY. http://doi.org/10.1007/978-1-4419-7988-9_1

Waterman, A. S. (1984). Identity formation: Discovery or creation? The Journal of Early Adolescence, 4, 329341. http://doi.org/10.1177/0272431684044004

Waterman, A. S. (1999). Identity, the identity statuses, and identity status development: A contemporary statement. Developmental Review, 19(4), 591-621. http://doi.org/10.1006/drev.1999.0493

Wenger, E. (1998). Communities of practice: Learning, meaning, and identity. Cambridge, [England]: Cambridge University Press.

Wilkins, J. L. M., \& Ma, X. (2003). Modeling change in student attitude toward and beliefs about mathematics. The Journal of Educational Research, 97(1), 52-63. http://doi.org/10.1080/00220670309596628

Wigfield, A., Eccles, J. S., Yoon, K. S., Harold, R. D., Arbreton, A. J., Freedman-Doan, C., \& Blumenfeld, P. C. (1997). Change in children's competence beliefs and subjective task values across the elementary school years: A 3-year study. Journal of educational psychology, 89(3), 451. http://doi.org/10.1037/00220663.89.3.451 